\title{
3D PRINTING METHODS AND TECHNOLOGIES: A SURVEY
}

\author{
Aayush Srivastava ${ }^{1}$, Akshat Singhal ${ }^{2}$, Aman Sachan ${ }^{3}$ \\ ${ }^{1,2,3}$ Author Student, Computer Engineering, Bharati Vidyapeeth Deemed University C.O.E, Pune, Maharashtra, India
}

\begin{abstract}
The thought of shaping your ideas into reality has achieved its literal meaning. A future where we can hold a tangible product in our hand which was the part of our imagination minutes ago is around the corner. The 3D Model printing isalready an exciting and successful venture. Manufacturing a product which you saw on the shelf of a local store, a complicated industrial part, a small and precise component of an aircraft, or just a prototype that gives shapes to your idea. In printing system domains, they majorly use two technologies either using CAD software to make the digital files or to use a three-dimensional scanner to scan a $3 D$ object to create a digital copy and to validate and implement the printed model. We are mainly having three techniques for $3 D$ model creation like - Selective Laser Sintering (SLS), Fused Deposition Modeling (FDM) and Stereo lithography (SLA). We present an illustrative study of the $3 D$ printing techniques, working of $3 D$ printer, their benefits and drawbacks, its impact on the economy.
\end{abstract}

Keywords: 3D, 3D Printing, 3D Graphics, 3D Printer, 3D Technology, 3D Modelling, 3D market

\section{INTRODUCTION}

$3 \mathrm{D}$ printing or additive printing is a process of making a solid three-dimensional model of any shape size using the additive process of adding layer after layer to create a three dimensional object. The additive method of printing or creating three dimensional object involves adding layers one after the other to create the structure rather than scraping or drilling material out of a solid piece (Subtractive printing). The layer is added iteratively till the time, the whole structure takes shape and is printed directly from the CAD model.Each of these layers represents a very thin horizontal cross section of the solid object.

Creation of CAD (computer aided design) file is the first step in the process, either a virtual design of the object is created in the software or a 3D scanner is used to scan the object and map it onto the CAD file. The CAD design process replaces the need to design physical prototypes out of malleable material which are generally used in modelling e.g. clay, Styrofoam etc. A designer uses the CAD program to make a digital model, which is then saved as a digital file in the computer in various formats. CAD program is used to create blue prints of the solid objects. CAD is what that makes 3D printing more dynamic.

Other than creating a CAD file, it is now possible to scan a 3D solid object and print an exact replica or modify the designs. Scanning a 3D object for printing is just like taking pictures of the object.

\section{LITERAURE REVIEW OF 3D PRINTING}

This idea of affording a portable and economical 3D printer making into existence in MIT in 1993. The technology to create a 3D model from a picture and allow a user to test a design before investing in a larger manufacturing program is called as stereo lithography which was first developed in 1984 by Charles Hull.Charles Hull developed this techniques of printing a 3D object by using digital data. The technique of stereo lithography was soon followed by many other techniques such as, the techniques of Fused Deposition Modelling (FDM) and Selective Laser Sintering (SLS) also became popular. A major breakthrough in this field came in the year 1993 when Massachusetts Institute of Technology (MIT) invented other techniques for three dimensional printing which was very similar to the way an inkjet printer prints. This was then followed by three major products, "Genesis" from Stratasys, "Actua 2100" from 3D Systems and "Z402" from Z Corporation. In 2005the first high definition color3D Printer came into existence, called as Spectrum Z510, developed by Z Corporation. The next major step forward in this field came in 2005 was the open-source collaboration with 3Dprinting. Dr.

RepRapan open-source initiative to build a 3D printer that can print most of its own components was developed by Adrian Bowyer at University of Bath. ReRap was an initiative to democratize $3 \mathrm{~d}$ printing market and make $3 \mathrm{D}$ printer available to everyone easily and cheaply.

\section{3D PRINTER WORKING}

$3 \mathrm{D}$ printing is additive process in which the object is created by placing successive layers of material until the whole object is created. The beginning of 3D printing starts with the development of computer simulated blueprint of the object which you want to produce. This object can be designed either on any 3D modeling software program such as AutoCAD (Computer Aided Design), Wings 3D, AutoDesk 123D etc. or with the use of any 3D scanner. 3D scanners like HandySCAN 3D ${ }^{\mathrm{TM}}$ are optimized to develop most precise measured replica objects. The object is model into hundreds or thousands of horizontal layers by any of the $3 \mathrm{D}$ modelling software. Then the same file is uploaded in the $3 \mathrm{D}$ printer to create the object layer by layer. 


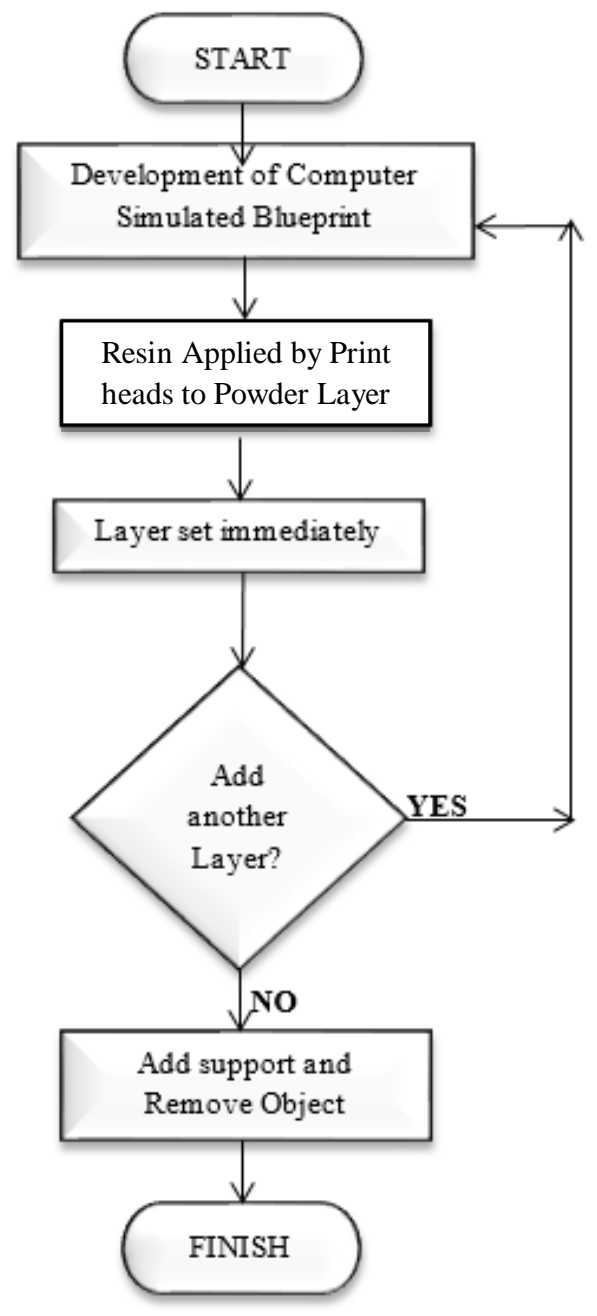

Fig 1: Working Flowchart

\section{METHODS AND TECHNOLOGY OF 3D} PRINTING

The $3 \mathrm{D}$ printer uses additive method which was the only method till 2012 but then was divided into sub categories to produce $3 \mathrm{D}$ objects printed. The different methods of $3 \mathrm{D}$ printing are: -

1. Selective Laser Sintering (SLS).

2. Fused Deposition Modelling (FDM).

3. Stereo lithography (SLA).

\subsection{Selective Laser Sintering (SLS)}

SLS was patented and developed by Dr. Carl Deckard at the University of Texas at Austin, under sponsorship of DARP in the mid- 1980s. In SLS technology High Power laser is used to fuse tiny particles of plastic, metal, ceramic or glass powder into desired 3D objects. Powdered material is fused layer by layer. The laser is controlled by the computer with the directions provided by the loaded digital file. The wasted powder act as support and can be used for the next printing. Example of SLS is Powder Bed Fusion.
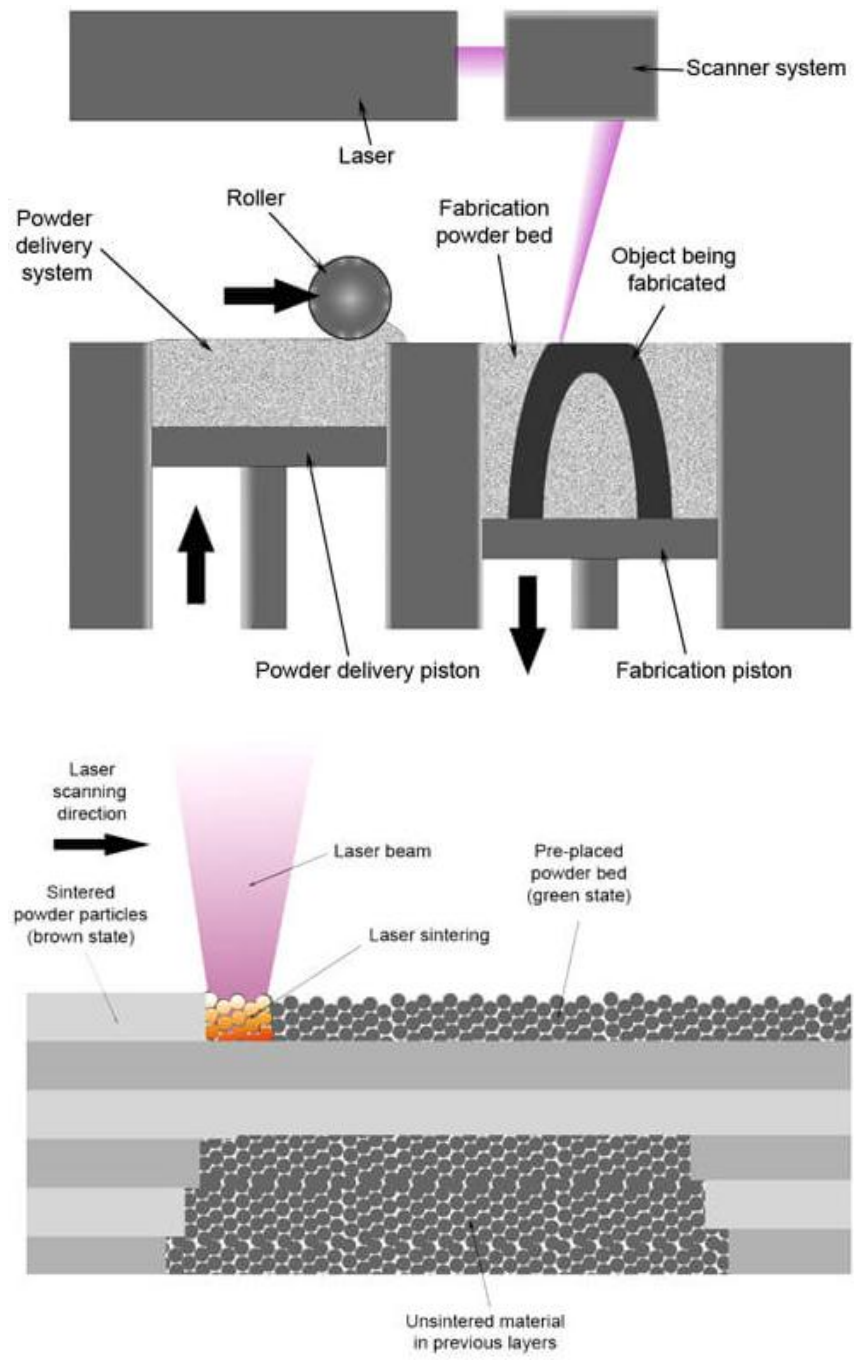

Fig 2: SLS system schematic

\subsection{Fused Deposition Modelling(FDM)}

FDM was invented and patented by Scott Crump in 1988. In FDM technology works using an extrusion nozzle which controls the flow of a plastic filament or metal wire from the nozzle. Then the nozzle is heated to melt the material and is moved in any directions depending on need. It nozzle is controlled by a computer-aided manufacturing (CAM) software package. And the material hardens immediately after coming out from the nozzle. Example of FDM is Material Extrusion.

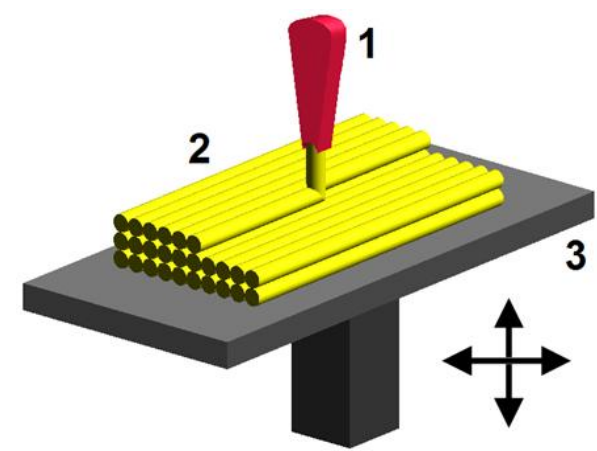

Fig 3: Fused Deposition Modelling (FDM)- a method of rapid prototyping. 
1. Nozzle ejecting molten material (plastic)

2. Deposited material (modelled part)

3. Controlled movable table

\subsection{Stereo Lithography (SLA)}

SLA was invented by Charles Hull in 1984 and patented in 1986. Stereolithography uses photo polymerization to produce a solid object from a liquid. To build the object's layers we use an ultraviolet laser and a vat of liquid ultraviolet curable photopolymer resin. As others, in SLA also object is made layered by layered and for every layer, the laser beam dashes over the surface of liquid resin. The ultraviolet laser light solidifies the pattern traced on the resin to join the layer below the new layer. Example for SLA is Vat Photopolymerisation.

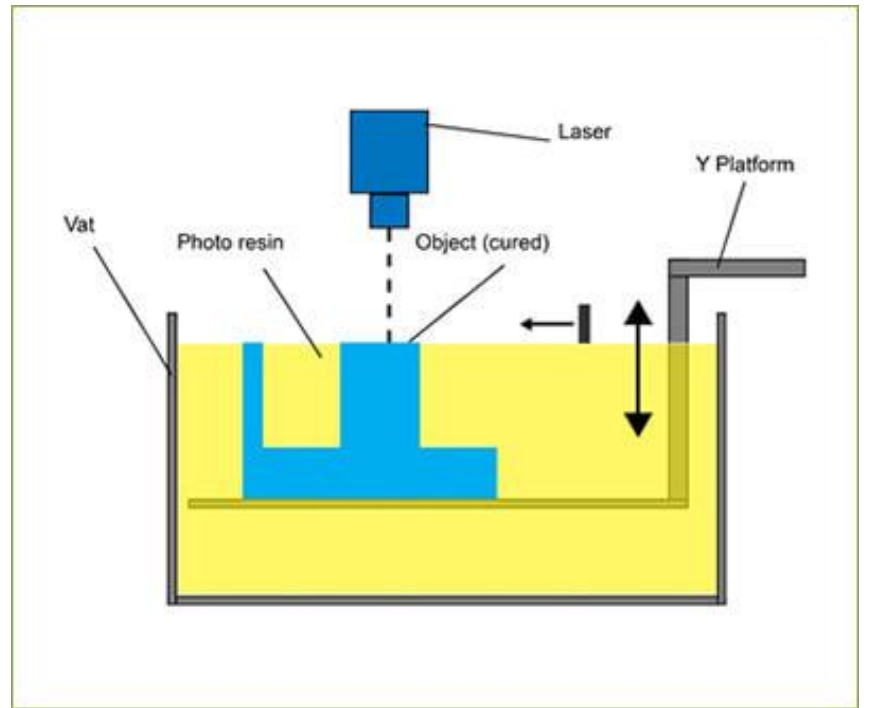

Fig 4: Vat Photopolymerisation schematics

Table 1 Comparison between the sub categories of additive method used to print $3 \mathrm{D}$ printed objects:

Table 1- Comparison between different methods

\begin{tabular}{|l|l|l|l|}
\hline Technologies & Supporting Structure & Material Used & Other Tools Used \\
\hline Selective Laser Sintering (SLS) & Not required & $\begin{array}{l}\text { Plastic, metal, ceramic or glass } \\
\text { powder }\end{array}$ & High Power laser \\
\hline Fused Deposition Modelling (FDM) & Required & Plastic filament or metal wire & Extrusion nozzle \\
\hline Stereo Lithography (SLA) & Not required & $\begin{array}{l}\text { A vat of liquid ultraviolet curable } \\
\text { photopolymer resin }\end{array}$ & Ultraviolet laser \\
\hline
\end{tabular}

\section{ADVANCED APPLICATIONS}

The technology introduced in the early 80's has a wide range of applications. 3D printing has basically took over important applications in our daily life as the tasks got simplified in terms of capital and is also effective in producing basic tools at small parameters. There are some important applications of 3D technology which are used in the market and some of them will be in near future. There are some advanced applications of technology that may have a great influence on people in near future:

\subsection{Lens for Smartphone Flashlight Booster}

3D printinghas made a big impact on the technology whether it is in consumer field or any other. Three big Italian entrepreneurs has developed a 'F.lens' or 'Flens' which is basically a flashlight enhancer used in the smartphones that can boost the flashlight power as much as by $10 \mathrm{x}$ and it is made possible by the $3 \mathrm{D}$ printed optic lenses. The Flens is basically a small, square-shaped device, and consists of a dedicated lens that is $3 \mathrm{D}$ printed using a plastic material with optical properties similar to PMMA.

\subsection{Navy Aircraft With 3D Printed Part}

It seems like US Navy has also come in the impact of 3D printing technology. After broad experiments of 3D printing on land and at sea, the navy has just revealed some plans for a test flight with a Boeing V-22 Osprey with dedicated 3D printed components. The tests have been organized by the Naval Air Systems and will be taking place in June'16.

\subsection{D Printed Parts In Space}

At present, NASA's space vehicle which is used for exploration consists of 70 3D printed parts and yet they are developed on the ground. Printing parts on-demand directly in space would expressively reduce the cost which is required to send a rocket in space with necessary replacement and overhaul tools.

\section{BENEFITS AND DRAWBACKS OF 3D PRINTING TECHNOLOGY}

Technology is a boon and also defined as the pool of techniques, abilities, methods etc. but it always comes with some benefits and drawbacks. In the similarmanner, 3D printing too has some benefits anddrawbacks. The positive side of $3 \mathrm{D}$ printing has a wide range of benefits which can be underlined as-

\subsection{Product According To A Customer Needs.}

3D printing technology basically offers an eclectic variety of manufactured products which can also be customized according to the customer's needs. 


\subsection{Low Cost Production.}

Initial setup cost is higher in producing any goods, but 3D printing has become quite cheaper and also the cost for $3 \mathrm{D}$ printing is still decreasing as the installation of $3 \mathrm{D}$ printers in homes, offices. And to mention, the cost for the customized products are same as the cost for the mass production products.

\subsection{Storage Space.}

With the advanced technologies, it is quite cheap and much faster to produce the goods which would be needed eventually. But in the case of 3D printing, only those products which are sold in the market are mass-produced and as a result the storage for excess products is less required leaving enough space for other products.

\subsection{More Employment.}

More manpower as in more engineers are required to design the $3 \mathrm{D}$ printers, and more care, usage has to be done by the technicians. And with the low cost for the manufacturing phase more products could be delivered in the market which would also create more jobs for the products shipment.

\section{The Negative Side}

The technology always has a negative side with the positive.It could be incorrectly used for destruction and exploitation if in wrong hands. With a great number of benefits, 3D printing could also face following drawbacks:

\section{(a) Inadequate materials.}

3D printers now, uses mostly plastic with other materials such as titanium, ceramics, nylon etc. Other materials and technology to manufacture goods through $3 \mathrm{D}$ printing are still under progress.

\section{(b) Unsafe items.}

3D printing could be used to create dangerous items such as knives, guns and many other items which may be used for security breaching.

\section{(c) Useless stuff.}

3D printing could lead to in making useless stuff which could harm the environment and also the wallets.

But fortunately for us, there are few new methods for recycling the objects automatically made by the $3 \mathrm{D}$ printers in the near future.

\section{CONCLUSION AND FUTURE SCOPE}

The 3D Printing technology is the new magic which has revolutionaries this era of technology. 3D printing has not only opened new doors in the field of modelling and designing it has also opened this universe of vast possibilities in other fields. The wide applications of this technology ranging from making parts for space station to making artificial bones for medical advancement 3D printing is finding applications in every field.
It is predicted that $3 \mathrm{D}$ technology will change the nature of business, because end users will be able to do much of their own manufacturing rather than buying parts from other companies. In future more $3 \mathrm{D}$ printers will have more options of color and material. By enhancing waste management, material used, tools and technology 3D printing will change the way of manufacturing products. In future by manipulating the atoms of substance like concrete, plastic, metal, glass etc. we can use the today's techniques to produce $3 \mathrm{D}$ objects.

\section{REFERENCES}

[1]http://www.nasa.gov/mission_pages/station/research /news/3Dratchet_wrench/\#.VNgQ7vmUeAw

[2]http://3Dprintingindustry.com/2015/01/24/upcycledvd drives-low-cost-3D-printer-cnc-machine/

[3]http://www.philforhumanity.com/3D_Printing.html [4]http://www.3Dprintingindustry.com/2015/01/15/syri ansoldier-successfully-fitted-titanium-3D-printedjaw/

[5]http://3Dprintingindustry.com/3D-printing-basicsfreebeginners-guide/benefits-commercial-value/

[6]Image source: Wikipedia from user Materialgeeza under Creative Commons Attribution-Share Alike 3.0 Unported license

[7]Image source: Wikipedia, made by user Zureks under CC Attribution-Share Alike 4.0 International license.

[8]Image source: lboro.ac.uk

[9]http://www.alliedmarketresearch.com/3D printingemerging-economies-china-india-UAE-brazilsouthafrica-market.

[10]http://www.inside3Dp.com/four countries emerging3Dprinting-giants/

[11]http://www.3Dprinterstocks.com/a-list-of-3Dprintingcompanies/

[12]http://www.industryweek.com/technology/18companies -leading-3-d-printingconversion\#slide-21field_images154531

[13]http://3Dprint.com/18633/3D-printersmanufacturing/

[14]http://www.stratasys.com/industries/education/4dprintin g-project

[15]http://www.yourstory.com/2014/07/3D-printingindia/

[16]http://www.smartprinting.co/3Dprintingnews/teleportati on-proved-possible-with-3D-printers/

[17]http://www.selfassemblylab.net/4DPrinting.php

[18]http://3dprinting.com/what-is-3d-printing/

[19]http://individual.troweprice.com/staticFiles/Retail/S hared/PDFs/3D_Printing_Infographic_FINAL.pdf

[20]http://www.hongkiat.com/blog/25-free-3d-modellingapplications-you-should-not-miss

[21]http://www.creaform3d.com/en/metrologysolutions/portable-3d-scanner-handyscan-3d

[22] http://www.openfabrication.org/ 


\section{BIOGRAPHIES}

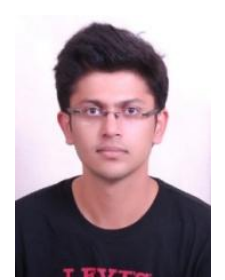

Aayush Srivastava pursuing B. Tech degree in Computer Engineering from Bharati Vidyapeeth Deemed University College of Engineering, Pune. His research interest are in $\mathrm{CAD}$ (Computer Aided Design) and Software Architecture.

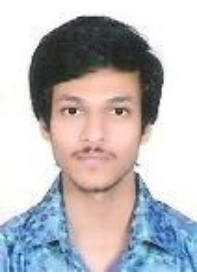

Akshat Singhal pursuing B. Tech degree in Computer Engineering from Bharati Vidyapeeth Deemed University College of Engineering, Pune. His research interest are in Database Design and Networking.

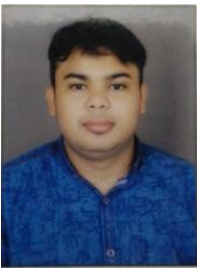

Aman Sachan pursuing B. Tech degree in Computer Engineering from Bharati Vidyapeeth Deemed University College of Engineering, Pune. His research interest are in Artificial Intelligence, Big Data, Networking and Security. 